\section{MUSEUM SPECIMENS FOR TEACHING PURPOSES ${ }^{1}$}

\section{III.}

I NOW pass to the second great division of museum preparations, those that are preserved in a fluid medium; the only way in which the greater fart of the structure of most animals, both vertebrate and invertebrate, can be kept from change and decomposition.

The first question for consideration is the best preservative medium. The one which has been most extensively used in all countries is alcohol. Various substitutes, as solutions of common salt, alum, bichloride of mercury, or arsenic, have been proposed and triell, chiefly on account of the expense of alcohol, and other slight disadvantages, but after a few trials these have generally been given up. At all events, the experience of alcohol in all the large museums of this country, has been so satisfactory compared to that of other media, that it is now alone used. The objection of expense which was caused by the high duty, has bet $n$ in a great neasure obviated by the permission to use "methylated" spirit, duty free, though some disadvantages have been thereby entailed.

There seems little doubt but that a mixture of alcohol and water (commonly known as "spirits of wine," or when spoken of in relation to anatomical purposes, as "spirit" only) of the projer strength will preserve an animal substance for an inde. finite length of time. There are specimens in the exhibition, (No. $3^{8} 78 \mathrm{a}$ ), belonging to the Museum of Anatomy of the Academy of Science at St. Petersburg, prepared by the celebrated Dutch anatomist Ruysch, and bought from him by the Czar Peter the Great, in 1717 , still in a perfect state of preservation. We have now in the Museum of the College of Surgeons many thousand preparations put up in the last century by John Hunter, and which appear to have undergone no changes beyond those which took place during the first few veaks of immersion in spirit, and which may be described as a certain amount of hardening and contraction of the tissues by coagulation of the albumen contained in them, and discharge of much of the natural colour.

The extent to which these changes take place depends very much upon the method with whach the specimen is treated in the first instance. Sometimes it is desirable to harden the structure rap:dly, as in preparations of hollow viscera, when the form alone is essential, in others, where preservation of the general appearance and the texture of the tissue is more requisite, and where further dissection is likeiy to be required, it is best to keep it as much as possible of the natural softness. The first condition is produced by immersing the preparation, when placed in the position in which it is to remain, in alcohol of the greatest strength, which afterwards may be diminished; the latter hy beyinning with a weak solution and gradually increasing the strength up to that finally used for permanent preservation.

The strength of the alcohol is estimated by its specific gravity, ascertained by the instrument called the hydrometer. But we io not speak of the actual specific gravity of physicists, but follow the conventional standard of the spirit-trade, the startingpoint being taken at what is called "proof" at a temperature of $60^{\circ} \mathrm{F}$., and the scale divided into degrees or "per-centages" above and below proof. By $\mathrm{I}$ per cent., or $\mathrm{I}$ degree under proof, is meant proof spirit with one-hundredth part (by bulk) of water. Spirit ro per cent. under proof is a spirit consisting of 90 parts of proof spirit and to of water. On the other hand, by ro per cent. over proof is meant that 100 parts (by bulk) of such spirit will require 10 parts of water to bring it to proof.

The "rectified spirit," as commonly so!d, is about 60 or 65 per cent. above proof. This is only used for hardening preparations.

For ordinary use in the museum, proof spirit is stiong enough, though to be quite on the safe side we generally use ro per cent. over proof, diluting the rectified spirit with distilled water iill it is reduced to the requisite strength, as ascertained by the

I.ecture at the Loan Collection of Scientific Apparatus, South Ken sungton, July 26,1876 , by F'rof. W. H. Flower, F. R.S., Conservator of the $M$ ssemin of the Royal College of Surgeons of England. Continued from p. 186 .

2 Methylated spisit is decidedly inferior in transparency and in absence $\bullet$ colour to pure spirit, and even if bright when first used, is apt to become iurbid afier a time. In a large establishment this can be to a great extent remedied by passing the' discolnured spirit throngh a still, but it would te very des rable to consider whether some ocher method could not he devised by which alcohol could be used for scientific purposes, withcut the neciessity of puying the present heavy duty of sixteen shillings and sixpence á gallon. hydrometer. This is the strength commonly used for all kind of preparations, though it might ${ }_{1}$ be varied with advantage in some cases.

In estimating the preservative power of spirit, consideration should be given to the bulk of the specimen, and especially the amount of water contained in its tissues, as compared with the quantity of spirit used. For instance, if a large solid mass of animal substance is placed in a jar little larger than sufficient to contain it, filled up with proof spirit, the amount of fluid contained in the specimen will so dilute the spirit that decomposition, especially of the interior of the specimen, to which the spirit cannot penetrate, will not be prevented, whereas a smaller specimen placed in the same jar of spirit will be preserved perfectly. Many collectors of objects of natural history do not altend sufficiently to these considerations, and hence the specimens become spoiled, much to their disappointment or $t_{1}$ ) that of their consignees. The way to obviate this is not to use stronger spirit, as that would harden the exterior of the specimen, and prevent the spirit penetrating to the centre, but to use greater bulk of spirit, and especially to change it, after a day or two, pouring awdy the old diluted spirit, and substituting fresh, repeating the process if necessary more than once.

When a specimen has once been thoroughly saturated with spirit, and its tissues hardened, a strength much below proof will be sufficient to preserve it. The nature of the specimen must also be taken into consideration. For instance, nerve tissue, as in the brains of animals, requires stronger spirit for its preserva. tion than ligamentous or fibrous tissues. Much will also depend upon the treshness of the specimen. If decomposition has already set in before it is placed in spirit, it will require much stronger spirit, and more frequent renewals than if it is fresh.

With most preparations it is desirable to cleanse them well before mounting them in spirit. They should be left a few hours or days (according to the temperature) in water frequently renewed, and the blood should be washed out of the large vessels, by means of a stream of water diuected through them. This wiil save to a large extent the discolcration of the spirit into which they are placed. When removed from the water they should be allowed to drain, and be gently dricd with a cloth before placing in the spirit, but no part of them must on any account, at any time during the process of preparation, be allowed to become actually $d r y$, otherwise dark stains which are quite irremovable will be produced. This precaution is most essential when they have been once in spirit, and are removed for examination or further dissection, as evaporation of the alcohol, and conseyuent desiccation of the preparation, takes place muck more rapidly than that of water.

In most cases it will be requisite to change the spirit once or oftener, before all the soluble colouring matter is given off from the preparation, and it can be permanently mounted. The discoloured spirit need not be wasted, as it can be perfectly restored by passing through the still.

To succeed in making a good anatomical preparation, much patience, neatness of hand, knowledge of the subject illustrated, and some artistic talent are required. No pains sinculd be spared to make it tell the lesson it is intended to convey in the most attractive and pleasing manner. Everything should be displayed as definitely and clearly as in a drawing, and there should be no appearance of negligence or want of finish in any part.

When an elaborate dissection is required, it must, at least in all its later stages, be carried on while the specimen is under spirit, fixed in a flat dish or basin. The small fragments of connective tissue which have to be remuved then thoat out from between the fibres of the muscles and the vessels which are to be preserved and exhibited, and they are carefully snipped off with fine curved scissors. A dissection which looks clean and highly funished as long as it is in air, when placed in fluid, becomes at once cloudy and obscure, from the floating up of these little particles. Hollow viscera, as hearts or stomachs, are distended by injecting their interior with strong spirit, tying or plugging the apertures by which it could escape, and placing them for several days in a vessel with the same duid. If all the requisite precautions are taken, they will then preserve their form, and the iuterior of their cavities can be exhibited, by cutting openings or "windows" through different parts of their walls. If from any cause a cavity cannot be made to contain spirit, it may be stuffed with cotion-wool or horse-hair during hardening. The preparation, when laid aside to harden, if not suspended, should be placed in a bed of cut!on wool adapted to its form, otherwise it will become irremtdiably flattened on the side on which it rests. 
Preparations are usually mounted in glass jars, open at the top, and with a foot below, and either circular or oval, i.e. flattened on two opposed sides. The form is selected according to that of the preparation. The ovals show off some preparations to greater advantage than round bottles, but have the disadvantage of being more expensive and being (especially when of large size) liable to crack spontaneously, and apparently without provocation, but probably in consequence of some alteration of temperature affecting the unequal tension of the outer and inner surface of the glass at the bent ends. ${ }^{x}$

The fine silk tbreads by which the preparation is to be sus. pended are brought over the edges of the jar, and passed beneath an ordinary thread tied round the groove, then returned and secured across the top of the jar. As threads fastened in this way occasionally are the means of causing leakage of the spirit, with which of course they are always salurated, some prefer to tie them to a piece of wood, or whalebone, fixed across the mouth of the jar. The only disadvantage of this is that it entails some additional trouble, and a reduction of the number of points of suspension which may be made use of in the other method.

There are two methods generally adopted for closing the upper end of the jars after the preparation is mounted in it. The oldest, and still very generally used, is by means of successive layers of bladder, tin foil, thin sheet lead, bladder again, and finally black varnish. The bladder must be macerated until it is partially decomposed, and then it will adhere firmly to the glass. This necessity makes the process a disagreeable and dirty one. The object of the tin foil is to protect the lead from the oxidisation which always takes place when the vapour of spirit comes in contact with it through the first layer of bladder, tin not being so acted upon. A layer of tin only wiould answer as well as the tin and lead, but if thick enough for the requisite strength, would be more expensive and less easily worked round the edges of the glass. The thin sheet of tin is gummed to the surface of the lead, and then they are cut together to the requisite size, and treated as one, the tin being of course placed downwards. The edges are firmly pressed down round the lip at the top of the bottle and into the groove, with pieces of box-wood shaped for the purpose. . Much of the success in closing the bottle depends upon the care with which this is done. Then the second layer of bladder is put on, and tied firmly with twine, round the groove at the top of the bottle. When thoroughly dry the twine is removed, and the edges of the bladder neatly trimmed with a knife ; it is afterwards coaced with one or two layers of black paint ard a layer of black japan varnish.

Bottles closed in this way often keep in the spirit for many years without any material alteration in its level, but there is generally a slight evaporation, so that they have to be watched, and whenever the spirit gets so low that the safety of the preparation is endangered, the old cover must be cut off, and the specimen remounted and closed in by the same process.

A more expeditious and cleaner process, which has also the advantage of admitting light to the top of the preparation and allowing it to be seen from above, is by the use of glass covers. The top of the bottie is ground smooth, and a cover of glass of thickness suited to the size of the bottle cut to fit it. Many praciical difficulties have been encountered in carrying out this process, but they have been mostly surmounted by experiment and perseverance, and it probably will in time entirely supersede the bladder and lead plan.

One cause of difficulty was the frequent breakage of bottles so fastened, upon changes of temperature; in the other plan, the top, being somewhat flexible, yields with the varying state of epransion of the contents of the jar, but the slass top is perfectly rigid, and if the pressure is too great must either separate from the bottle or break. This occurs chiefly in large bottles where the bulk of spirit is great, and consequently its expansive power out of proportion to the strength of the glass. This can be obviated to a great extent by not filling the bottle completely, as then the layer of air at the top, being far more compressible than the spirit, acts as a sort of buffer between the boitle and the glass; but in large bottles we generally take the furtber precaution of a small safety-valve; a hole drilled through the cover, with a loosely fitting stopper to check too

The greatest desideratum in putting up wet preparations is a durable glass jar with flat sides, so that the distortion of the object caused by the refraction through the curved surface of the glass may be avoided. Built up cells do very well for small objects, but they are very expensive, and generally fail when tried on a large scale. The subject still offers a good field great evaporation, or the ingress of dirt. Through this hole the jar can be filled up with spirit, when required, without the necessity of disturting the preparation, as in the old process.

A second difficulty with glass-covered jars was to find a cement to fix the top, at the same time easy of application and not dissolved or weakened by the spirit. Isinglass dissolved in strong acetic acid, pure gutta percha, a mixture of pitch and gutta percha, and other substances, have been successively used in the Museum of the College of Surgeons, but finally we have given them all up for a composition sold as "Rock marine glue." 1 It is applied in a melted state, the edres of the glass cover being also heated. A small gas jet fixed on a flexible tube greatly facilitates this process.

The suspending threads can either be fixed to a glass rod placed across the top of the bottle just below the glass cover, the ends of which are let into notches cut for the purpose on opposite sides of the inside of the upper rim of the jar, or they can be brought out between the top of the jar and the glass cover, embedded in the cement, and secured by a string tied round the top of the bottle till the cement is hard, when they can be cut off close to the outer edge of the cover, and the securing string removed. The preparation is then finished by neatly painting the edge of the covering glass and cement, and the neck of the bottle for a short distance below, with two or three coats of black varnish.

For displaying different parts of the preparation, especially canals or cavities, black and white hogs' bristles and variously coloured glass rods are used. Delicate preparations, which cannot be kept in position if simply suspended, are fastened by stitches to thin transparent plates of mica, or to opaque coloured slabs of wax, or cardboard. Black or blue are the colours generally preferred, as in greatest contrast to the usual colour of preparations, as shown in the beautiful series of dissections illustrating the anatomy of the frog $(3,904 c)$ contributed by Prof. Huxley.

I have said nothing yet about injecting preparations, a process necessary in order to display the course and distribution of blood.vessels. There are two kinds of injections, fine and coarse ; the former fills the capillary vessels, and for preparations intended to be seen with the naked eye, gives a blush of the colour used to the tissue, and is chiefly valuable as indicating the relative amount of vascularity of contiguous tissues. For microscopical investigations it is invaluable, and the methods employed and the materials used are fully detailed in all works devoted to microscopical maripulation. Coarse injection is intended only to show the vessels visible to the cye, and not io enter into the capillaries. Size, so generally used as a basis for fine injections, is not so satisfactory in this case, as if in any bulk it contracts in the spirit. The best material (introduced by Dr. J. B. Pettigrew, F.R.S., when Assistent in the Museum of the College of Surgeons) is fine plaster of Paris, coloured with vermilion or ultramarine, according as the tint of red or blue is required. It is mixed with water, as in taking casts, though of rather a more fiuid consistence, and of course must be injected immediately, or it will set in the syringe. It has the great advantage of heing use 1 cold. It is rather brittle when set, and the vessels sbould be handled with care, but it may be made more tenacious by tic addition of some glue or isinglass to the water with which the plaster is mixed.

The distinction between two different kinds of tiswue is sometimes well shown by staining the preparation. Some grood examples are exhibited by the Anatomical Museum of the University of Oxford. The head of a stugeon (Nos. 3,837 and 3.838, prepared by Mr. Robertson) has been immersed for a short time in a solution of carmine, and the cartilage and connective tissue has received the colour, while the bones retain their natural white hue. The distinction between them, which otherwise would scarcely be perceptible in the bottie, is thus very clearly brought out.

The third and last great division of museum specimens for teaching purposes, illustrated by this exhibition, is that which comprises models and casts of natural objects, and under the same heading drawings and diagrams may le includer.

As a general rule, models should never be used for teaching if actual specimens can be obtained and exhibited; but there are numerous cases in which the object is of so perishable a nature, that it cannot be preserved efficiently by any of the methods above described. Many objects are so scarce that it is quite out of the power of most museums to possess any representations of them, except as copies of the originals.

I It is bought from Rockhill and Co., ro, Blackfriars Road. 
There are also others so small, that for lectures and demonstrations an enlarged model is of very great assistance.

What may be done in teaching natural history by means of models and coloured casts is admirably shom in Mr. Frank Buckland's museum in this building, where may be seen accurate reprecentation of many of the succies of Cetacea and larger fish of our seas, giving a more completc idea of their size, form, and colotir, than has ever been produced by any other method. The reduced models of animals and men of various races exhibited by the Committee of the Pedagogical Museum of Russia are also interesting, and must be useful aids to school teaching. By what other means, for instance, could the singular form of such an animal as the Greenland right-whale he brought before a class of pupils? I would also call attention to the well-known anatomical models of Dr. Auzoux, of Paris (which by the way are not very fully represented in the present exhibition by Nos. 3,829 $a$ to $d$ ) ; to the models illustrating the development of the trout, by Dr. A. Ziegler, of Freiburg (No. 3.839); to the enlarged models of blood corpuscles of different animals for illustrating their form and size, by Prof. $\mathrm{H}$. Wolcker, of Halle (No. 3,893); to the models of Radiolaria in papier máché, by V. Fric, of Prague (No. 3.865); to the numerous anatomical models of Strembitsky in the Russian collection, of Rammé and Todtmann, of Hamburg (Nos. 3,868-3,877); and of Tramond, of Paris (Nos. 3,923$3,925)$; to the casts of different parts of the human body dissected, by Steger and Honikel, of Leipzig (Nos. 3,840-3,842); and to the models by various exhibitors illustrating the structure of flowers and seeds.

With reference to such models, the importance of accuracy of execution cannot be too strongly insisted upon. With a cast of course there is not much chance of error, but for the accuracy of a model, especially when on a different scale from the original, we are entirely dependent upon the artist's skill and care. The unly fault to be found with most of those in the exhibition is that they are rather too rough in execution to be pleasing to the eye, but it has been in most cases an object to produce them at such a low price, as would riot be compatible with fine workmanship.

Although $I$ have only been able in the time allotted to glance bi iefly at the various branches of the subject which I have been requested to expound, I trust that some suggestions have been given in this lecture which will be found of use to those who have the care of collections, and that I have succeeded in showing that the art of preparing, preserving, and displaying specimens in museums is one which deserves to be more fully cultivated than it has hitherto, as a most important adjunct to the difusion of biological knowledge.

\section{OUR ASTRONOMICAL COLUMN}

The New Stak in Cranus.--Prof. Schmidt has publisher details of his observations of this star from November 24, the date of discovery, to December $\mathrm{x}_{5}$, and has also put upon ricord the dates, between November I and 20, when he had examined the constellation Cygnus, with the view to show that a star as bright as the fifth magnitude could not have escaped his notice, and therefore that the rise of the new one to the thiid magnitule must have been very rapid, as also appears to have been the case with $T$ Corona in 1866 . On the evening of its discovery the star was strong golden yellow, and writing on December 9, Herr Schmidt states it had always been of a deep yellow, but at no time exhibited the redness of its neighbour, 75 Cygni. The following are the magnitudes on different nights aid determined at Athens by careful comparisons with $\rho, \pi^{2}, \tau, \zeta$ and $\phi$ Cygni, and $\eta$ Pegasi :--

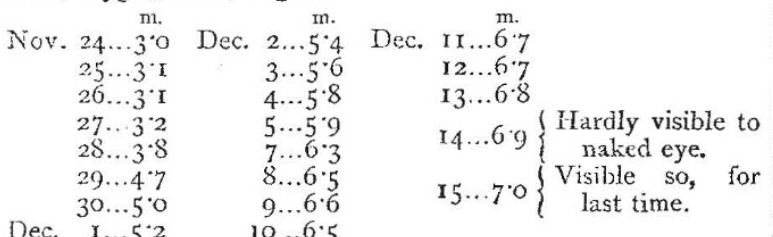

On the evening of December $3 \mathrm{I}$ the new star was about $7 \mathrm{~m}$. and very decidedly orange. It has but slowly diminished during the last three weeks.

New Varzable Star in CeTUS.-Mr. J. E. Gore, writing from Umballa, Punjab, on November 28, draws attention to a

star entered on Harding's atlas as a sixth magnitude, about $\mathrm{I}_{\frac{1}{4}}^{\circ}$ distant from $59 v$ Ceti, and 13 ' s.p. Lalande 3590. On November 18 , this star was only $8 \mathrm{~m}$., considerably fainter than a $7 \mathrm{~m}$. star shown by Harding, closely preceding $v$.

This star is not in any of the catalogues, nor in. Schjellerup's list in No. viii. of the publications of the Astronomische Gesellschaft. Reading off from Harding and reducing to $1877^{\circ} 0$ its position is in R.A. Ih. $50 \mathrm{~m}$. 13s., N.P.D. $110^{\circ} 59^{\prime}$.

De Vico's Comet of SHor'T Period.-It was remarked in this column last week, that unless the orbit of De Vico's comet of 1844 has undergone some violent perturbation, a perihelion passage may be expected to occur during the year just commenced. It appears, however, that the chances of detecting the comet, should it arrive at its least distance from the sun during the first three months of the year are very small indeed, and hence, unfortunately if the comet is not found between July and December, it cannot be inferred with any degree of certainty that it has not passed its perihelion within the twelvemonth. The following places are calculated from Prof. Briinnow's last orbit for 1844 , reduced to the equinox of 1872 , supposing the arrival at perihelion to fall either on the date mentioned or thirty days before or after it. $\Delta$ is the comet's distance from the earth.

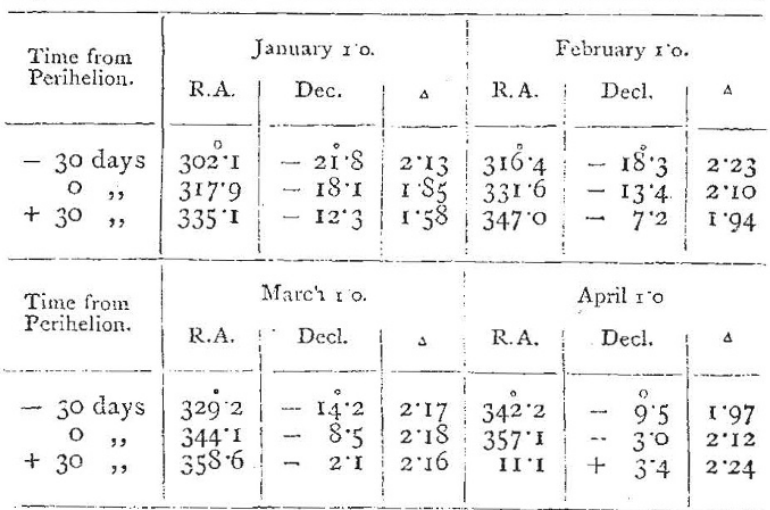

The Total Solar Eclipse of STIKLASTad, IOzO, AUGUST 3I.-The circumstances under which this eclipse occurred are given by Prof. Hansteen, of Christiania, in Ergänzungs-Heft zu den Astronomische Nachrichten, p. 42, with elements computed from the tables of Burckhardt and Carlini. Sir George Airy has also published elements of the eclipse, resulting from Hansen's calculations from his Solar and Luns: Tables, as an addendum to the paper on the eclipses of Agathocles, \&c., in vol. 26 of the Royal Astronomical Society's Memoirs, having previously drawn atteution to the circumstance that the eclipse of Stiklastad, from the narrowness of the belt of totality and its having been total at a well-defined poirit, might, in combination with the eclipse at Larissa, 1.c. 557, May 19 , be of much value in throwing light upon corrections possibly re. quired for the lunar tables.

The following elements of this eclipse are founded upon the same system of calculation for the moon's places, to which we lately referred as having been applied to the Nineveh eclipse of B.C. 763 , with the sun's place from Sir George Airy's paper :G.M.T. of conjunction in R.A., I030, Aug. 31, at Ih. 20m. $40 \mathrm{O}$.

R.A.

Moon's bourly motion in K. $\mathrm{A}$.

Sun's

Moon's declination" ... "...

Sun's

Moon's bourly motion in decl.

Sun's

Moon's horizontal parallax "...

Sun's ", ., ...

Moon's true semi-diameter $\ldots$

Sun's

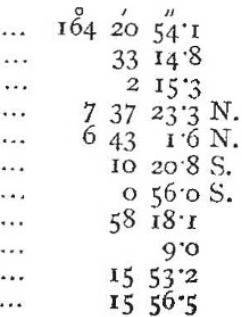

